\title{
Mountain range specific analog weather forecast model for northwest Himalaya in India
}

\author{
D Singh* and A GANJU \\ Research and Development Centre, Snow and Avalanche Study Establishment, Chandigarh 160 036, India. \\ *e-mail: dan_@rediffmail.com
}

\begin{abstract}
Mountain range specific analog weather forecast model is developed utilizing surface weather observations of reference stations in each mountain range in northwest Himalaya (NW-Himalaya). The model searches past similar cases from historical dataset of reference observatory in each mountain range based on current situation. The searched past similar cases of each mountain range are used to draw weather forecast for that mountain range in operational weather forecasting mode, three days in advance. The developed analog weather forecast model is tested with the independent dataset of more than 717 days (542 days for Pir Panjal range in HP) of the past 4 winters (2003-2004 to 2006-2007). Independent test results are reasonably good and suggest that there is some possibility of forecasting weather in operational weather forecasting mode employing analog method over different mountain ranges in NW-Himalaya. Significant difference in overall accuracy of the model is found for prediction of snow day and no-snow day over different mountain ranges, when weather is predicted under snow day and no-snow day weather forecast categories respectively. In the same mountain range, significant difference is also found in overall accuracy of the model for prediction of snow day and no-snow day for different areas. This can be attributed to their geographical position and topographical differences. The analog weather forecast model performs better than persistence and climatological forecast for day-1 predictions for all the mountain ranges except Karakoram range in NW-Himalaya. The developed analog weather forecast model may help as a guidance tool for forecasting weather in operational weather forecasting mode in different mountain ranges in NW-Himalaya.
\end{abstract}

\section{Introduction}

Western Himalaya comprises of complex mountain ranges and diverse snow climatic zones (Sharma and Ganju 2000). High variability in the surface weather elements such as temperature and precipitation in the complex mountain ranges of northwest Himalaya (NW-Himalaya) poses a significant challenge to weather and avalanche forecasters to predict them accurately over a mountain range or different areas in the same mountain range. Area specific weather forecasts are of primary importance for uninterrupted and safe movements, various road management activities and for better assessment of avalanche danger situation during the winter period (November to April). Weather forecasting in the context of avalanche forecasting can be viewed as an initial essential process to begin assessment of an avalanche danger situation for a given area and desired time. Since, avalanche occurrence in any area depends highly on weather and its various elements (Perla 1970; McClung and Schaerer 1993). Keeping the above facts in mind, mountain range specific analog weather forecast model is developed and further improvements are under progress.

The primary focus of this paper is to study the predictability of weather in operational weather forecasting mode employing the analog method and to study the possibility of forecasting weather

Keywords. Weather; weather forecasting; climatological; persistence; analog weather forecasting. 
Table 1. Practiced operational weather forecast for $N W$-Himalaya in India.

\begin{tabular}{|c|c|c|c|c|}
\hline No. & Operational weather forecast category & $\begin{array}{l}\text { Name } \\
\text { assigned }\end{array}$ & $\begin{array}{c}\text { Snowfall amount } \\
\text { in } 24 \mathrm{~h}\end{array}$ & $\begin{array}{c}\text { Qualitative weather } \\
\text { forecast category for } \\
\text { verification }\end{array}$ \\
\hline 1 & Fair weather & A & - & No-snow day \\
\hline 2 & Fair to partly cloudy weather & B & - & \\
\hline 3 & Partly cloudy to cloudy weather & $\mathrm{C}$ & - & \\
\hline 4 & Cloudy weather & $\mathrm{D}$ & - & \\
\hline 5 & $\begin{array}{c}\text { Cloudy weather with very light to } \\
\text { light snowfall at isolated places }\end{array}$ & $\mathrm{E}$ & $\begin{array}{r}>0.0-\leqq 7.4 \mathrm{~cm} \\
\quad(<25 \% \text { area })\end{array}$ & \\
\hline 6 & Cloudy weather with very light snowfall & $\mathrm{F}$ & $0-2.4 \mathrm{~cm}$ & Snow day \\
\hline 7 & Cloudy weather with light snowfall & G & $2.5-7.4 \mathrm{~cm}$ & \\
\hline 8 & Cloudy weather with moderate snowfall & $\mathrm{H}$ & $7.5-35.5 \mathrm{~cm}$ & \\
\hline 9 & Cloudy weather with nearly heavy snowfall & $\mathrm{I}$ & $35.6-64.4 \mathrm{~cm}$ & \\
\hline 10 & Cloudy weather with heavy snowfall & $\mathrm{J}$ & $64.5-124.4 \mathrm{~cm}$ & \\
\hline 11 & Cloudy weather with very heavy snowfall & K & $>124.4 \mathrm{~cm}$ & \\
\hline
\end{tabular}

over different mountain ranges and different areas of the same mountain range in NW-Himalaya. For this particular purpose, the developed ana$\log$ weather forecast model has been tested with the independent dataset of more than 717 days (542 days for Pir Panjal range in HP) of the past 4 winters (winter 2003-04 to winter 2006-07) for different mountain ranges and different areas in the same mountain range in NW-Himalaya. The erroneous data of winter 2004-05 for Pir Panjal range in HP is not considered. The model verification results for qualitative weather (snow day/no-snow day) and quantitative categorical snowfall prediction (quantitative snowfall category) and test results for drawing weather forecast in operational weather forecasting mode are discussed. The forecasts by the analog weather forecast model are also compared with the forecasts based on persistence (hereafter persistence forecast) and climatology (hereafter climatological forecast) for qualitative weather and quantitative categorical snowfall prediction for each mountain range for day-1 predictions. The results are briefly discussed in this paper.

\section{Study area and model data}

In this study, an attempt is made to predict weather over different mountain ranges of NWHimalaya in operational weather forecasting mode (table 1) employing analog method during the winter period (November to April). The analog method is based on surface weather observations (appendix A) only. This is primarily due to unavailability of the database of satellite data. Only those areas in the different mountain ranges of NW-Himalaya (figure 1) are considered in which Snow and Avalanche Study Establishment (SASE) is actively involved in weather and avalanche forecasting, and past data of surface weather observations are available. Our study area falls in Samsabari range, Pir Panjal range, great Himalayan range, Karakoram range in Jammu and Kashmir (J\&K) and it covers Pir Panjal range and great Himalayan range in Himachal Pradesh (HP). The study area in Pir Panjal range and great Himalayan range falls at two different places (HP and J\&K). Both the areas of Pir Panjal range and great Himalayan range have been considered to study the difference in the predictability of weather in different areas of the same mountain range by analog weather forecast model. The detailed characteristics and snow climatology of different mountain ranges are briefly discussed in Sharma and Ganju (2000). Sharma and Ganju (2000) divided western Himalaya into three major snow climatic zones, viz., lower Himalayan zone, middle Himalayan zone and upper Himalayan zone. The lower Himalayan zone is characterized as the zone of warm temperature, high precipitation and short winter period. It mainly covers Pir Panjal range in $\mathrm{J} \& \mathrm{~K}$, and the lower altitudes of the windward side of the same range in HP. These areas have an average height of 2000 to $4000 \mathrm{~m}$. The middle Himalayan zone is characterized by cold temperature, highest mountain peaks and numerous glaciers. The area falling in this zone is the great Himalayan range in $\mathrm{J} \& \mathrm{~K}$ and the upper reaches of Pir Panjal range in HP. This zone has an average height of $3500 \mathrm{~m}$. The upper Himalayan zone is characterized by steep peaks and glaciated valleys and climatic conditions are closer to polar conditions. The average height of this zone is about $5000 \mathrm{~m}$ and this zone covers the leeward side of great Himalayan range, Zanskar range and Karakoram range.

This study is aimed at the prediction of weather during winter using surface weather observations. 


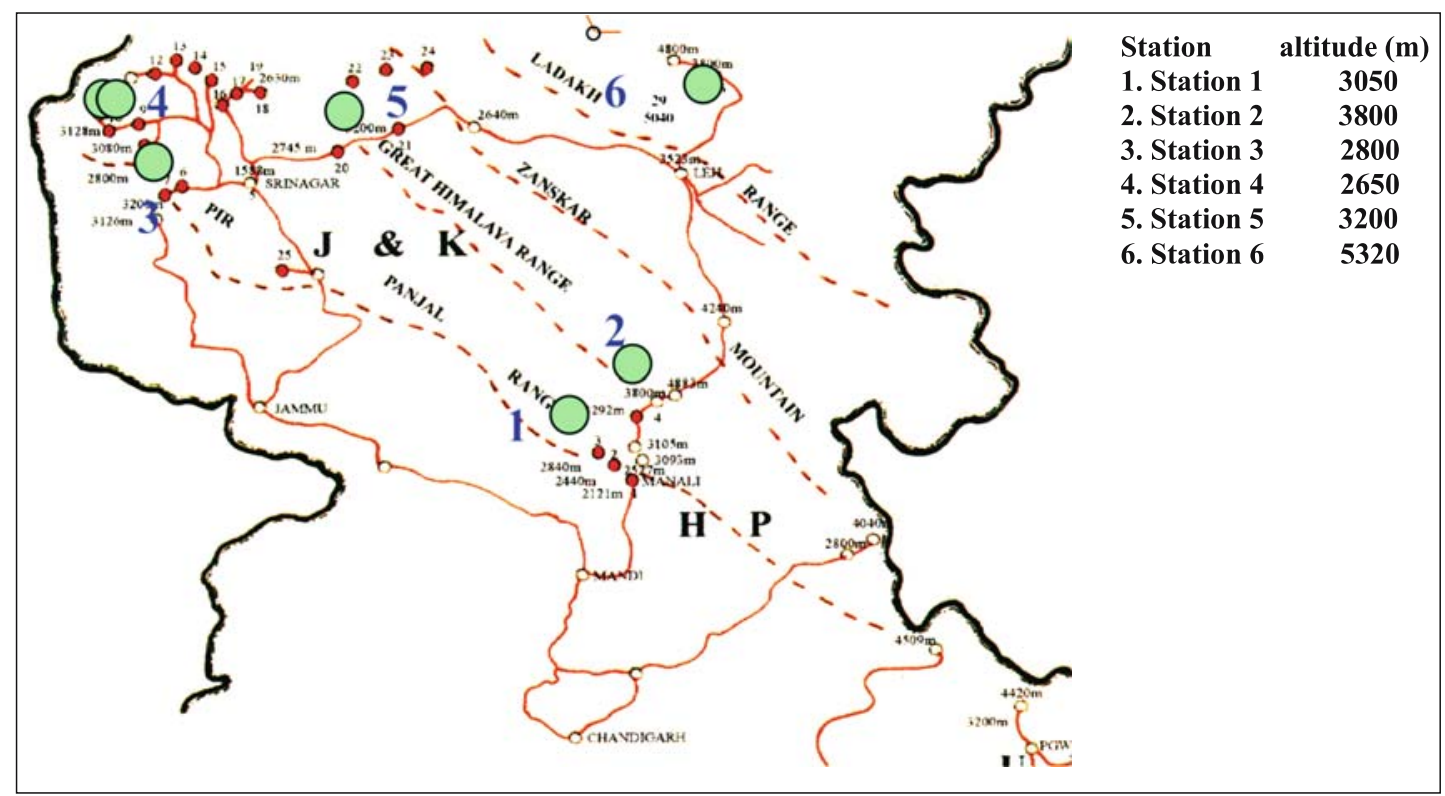

Figure 1. Representative observatory in different mountain ranges and areas in NW-Himalaya.

Table 2. Surface weather observations used for development of the analog weather forecast model and climatology of snow and no-snow day $\left(\left(T_{x}=\right.\right.$ mean maximum temperature, $T_{n}=$ mean minimum temperature, $W_{\text {avg }}=$ average wind speed, $F S_{24 \mathrm{~h}}=$ Snowfall in $24 \mathrm{~h}$ duration).

\begin{tabular}{|c|c|c|c|c|c|c|c|}
\hline \multirow[b]{2}{*}{ Mountain range/area } & \multirow[b]{2}{*}{ Winter period } & \multirow{2}{*}{$\begin{array}{c}\text { Number of } \\
\text { winters }\end{array}$} & \multicolumn{5}{|c|}{ Climatology } \\
\hline & & & Day & $T_{x}$ & $T_{n}$ & $W_{\text {avg }}$ & $F S_{24 \mathrm{~h}}$ \\
\hline \multirow[t]{2}{*}{ Samsabari range $(\mathrm{J} \& \mathrm{~K})$} & \multirow[t]{2}{*}{$1991-92$ to $2002-03$} & \multirow[t]{2}{*}{11} & Snow day & 1.4 & -3.2 & 1.4 & 21.3 \\
\hline & & & No-snow day & 7.5 & -0.8 & 1.5 & 0.0 \\
\hline \multirow[t]{2}{*}{ Pir Panjal range (HP) } & \multirow[t]{2}{*}{$1989-90$ to $2002-03$} & \multirow[t]{2}{*}{14} & Snow day & 2.2 & -4.1 & 2.6 & 26.7 \\
\hline & & & No-snow day & 8.6 & -1.2 & 3.3 & 0.0 \\
\hline \multirow[t]{2}{*}{ Pir Panjal range $(\mathrm{J} \& \mathrm{~K})$} & \multirow[t]{2}{*}{$1995-96$ to $2002-03$} & \multirow[t]{2}{*}{8} & Snow day & 0.8 & -5.1 & 2.0 & 17.5 \\
\hline & & & No-snow day & 6.2 & -4.7 & 2.2 & 0.0 \\
\hline \multirow[t]{2}{*}{ Great Himalayan range (HP) } & \multirow[t]{2}{*}{$1983-84$ to $2002-03$} & \multirow[t]{2}{*}{17} & Snow day & -0.9 & -10.3 & 2.5 & 10.2 \\
\hline & & & No-snow day & 1.9 & -12.4 & 2.0 & 0.0 \\
\hline \multirow[t]{2}{*}{ Great Himalayan range $(\mathrm{J} \& \mathrm{~K})$} & \multirow[t]{2}{*}{$1989-90$ to $2002-03$} & \multirow[t]{2}{*}{14} & Snow day & -0.7 & -10.9 & 1.0 & 10.0 \\
\hline & & & No-snow day & 2.2 & -14.5 & 0.9 & 0.0 \\
\hline \multirow[t]{2}{*}{ Karakoram range } & \multirow[t]{2}{*}{$1987-88$ to $2002-03$} & \multirow[t]{2}{*}{15} & Snow day & -11.8 & -22.3 & 6.5 & 5.1 \\
\hline & & & No-snow day & -10.8 & -24.4 & 5.6 & 0.0 \\
\hline
\end{tabular}

Accordingly, we have considered surface weather observations, measured twice daily at $08: 30 \mathrm{~h}$ and $17: 30 \mathrm{~h}$, of the winter period of a representative observatory in each mountain range and area for development and independent testing of the ana$\log$ weather forecast model. In total, the data of 6 observatories located in different mountain ranges and different areas in the same mountain range are considered. Past data for different mountain ranges and different areas in the same mountain range are not available for the same number of winters and is partially incomplete (Singh et al 2005). Therefore, available data prior to winter 2002-2003 for each mountain range and area is utilized for development of the analog model which, corresponds to data of 8 to 17 winters (table 2). The detailed climatology of snow day and no-snow day for each reference observatory in each mountain range and area is given in table 2. Mean maximum temperature of snow day is lower than mean maximum temperature of no-snow day for each mountain range and area (table 2). Mean minimum temperature of snow day is lower than mean minimum temperature of no-snow day for Samsabari range and Pir Panjal range. However, the mean minimum temperature of snow day is higher than mean minimum temperature of no-snow day for great Himalayan range 
and Karakoram range (table 2). Mean snowfall in Pir Panjal range of HP is higher than any other mountain range and area in NW-Himalaya.

\section{Analog weather forecast model}

Analog forecasting (AF) consists of searching for analog situations to the present or preceding situation and then predicting weather for forthcoming periods based on similar cases of the past. The method of analogs has been widely used for prediction of weather and its various elements (Zorita and Von Storch 1999; Wilby and Wigley 1997; Van den Dool 1989).

We employ the analog method for forecasting weather over different mountain ranges and different areas of the same mountain range in NWHimalaya in operational forecasting mode using surface weather observations of the representative observatory in each mountain range and area. The analog situations to the current situation are searched based on Euclidean distance metric (Singh et al 2005).

$x_{i}=$ vector of $m$ measurements for day $i$

$$
d_{i j}=\sqrt{\sum_{k=1}^{m}\left(x_{i k}-x_{j k}\right)^{2}}
$$

distance between day $x_{i}$ and $x_{j}$.

Based on the above distance metric, 10 best analog situations (10 days with least distances) are searched from historical dataset. The date and state of observed weather (snow day with snowfall amount in the next $24 \mathrm{~h} /$ no-snow day) for each analog situation is retained. In addition to the ten best analog situations, we search preceding situations and two successive situations corresponding to the ten best analog situations from historical dataset. The preceding situation and two successive situations corresponding to each analog situation represent the state of observed weather (snow day with snowfall amount in next $24 \mathrm{~h} /$ no-snow day) at previous measurement time and at two successive measurement times. The date and state of the observed weather for preceding and successive situations are retained along with the ten analog situations. The preceding situation and successive situations corresponding to each analog situation are searched to retrace the past dynamic behaviour of the atmosphere under similar conditions of the surface weather observations (how atmosphere has changed its state under similar conditions of the surface weather observations in the past). This offers the possibility of forecasting weather for more than one day (next $24 \mathrm{~h}$ ) in advance employing the analog method in absence of availability of surface weather parameters for day- 2 and day-3.

It may be expected that atmosphere will behave somewhat in a similar fashion as in the past under similar conditions of surface weather observations. This is equivalent to considering atmosphere as its own model. Therefore, analog situations may be considered as the representative of weather for day-1 forecast (next $24 \mathrm{~h}$ ), next situations to ana$\log$ situations as the representative of weather for day-2 (24-48 h) and next to next situations to analog situations as the representative of weather for day-3 (48-72 h). The probability of snowfall for day-1, day-2 and day-3 is computed from the searched analog situations using the following expression (Singh and Ganju 2004)

$$
P_{\mathrm{d} 1, \mathrm{~d} 2, \mathrm{~d} 3}=\frac{\sum_{r=1}^{N}(N-r+1) \times n_{r}}{\sum_{r=1}^{N}(N-r+1)} \times 100 \%,
$$

where $N=$ number of analog situations (10 in present case), $r$ is rank of the analog situation ( 1 to 10 in present case) and $n_{r}$ is 1.0 if $r$ th analog situation is snow day otherwise 0.0 .

While predicting the weather for three consecutive days, it is important to consider the preceding situations (Singh and Ganju 2006). Thus, the decision criterion of the analog weather forecast model for prediction of weather for day-1, day-2 and day-3 is defined as:

$$
D_{\mathrm{d} 1, \mathrm{~d} 2, \mathrm{~d} 3}=\frac{1}{3} \times P_{n-1, \mathrm{~d}_{1}, \mathrm{~d} 2, \mathrm{~d} 3}+\frac{2}{3} \times P_{n, \mathrm{~d} 1, \mathrm{~d} 2, \mathrm{~d} 3},
$$

where $P_{n}$, is the probability of snowfall for the day under consideration and $P_{n-1}$ is the probability of snowfall for the previous day.

The developed analog weather forecast model is run for each day of model development data (table 2) for each mountain range and area, and value of $D_{\mathrm{d} 1, \mathrm{~d} 2, \mathrm{~d} 3}$ is computed for day- 1 , day- 2 and day-3. Threshold values of the decision criterion of the model $\left(\mathrm{D}_{\mathrm{d} 1, \mathrm{~d} 2, \mathrm{~d} 3}\right)$ were decided and fixed for forecasting weather under snow day and nosnow day weather forecast categories for day-1, day-2 and day- 3 predictions (table 1 ). These are values of the decision criterion of the model for which performance of the analog weather forecast model is found best for classification of snow day and no-snow day for model development data. 
Days classified under no-snow day weather forecast category are further classified into different operational weather forecast categories based on different threshold values of the decision criterion of the model for them. These are values of the decision criterion of the model for which accuracy of classification of no-snow day is found best under each operational weather forecast category belonging to no-snow day category. The developed analog weather forecast model based on the value of $D_{d 1, d 2, d 3}$ predicts weather under different qualitative weather forecast categories over different mountain ranges and different areas in the same mountain range three days in advance as the following:

$$
\begin{aligned}
& \begin{cases}\mathrm{A}_{\mathrm{d} 1, \mathrm{~d} 2, \mathrm{~d} 3}, & 0 \leqq \mathrm{D}_{\mathrm{d} 1, \mathrm{~d} 2, \mathrm{~d} 3} \\
& \leqq \mathrm{D}_{\mathrm{a}, \mathrm{d} 1, \mathrm{~d} 2, \mathrm{~d} 3}^{\mathrm{th}}\end{cases} \\
& \text { weather category A } \\
& \begin{cases}\mathrm{B}_{\mathrm{d} 1, \mathrm{~d} 2, \mathrm{~d} 3}, & \mathrm{D}_{a, \mathrm{~d} 1, \mathrm{~d} 2, \mathrm{~d} 3}^{\mathrm{th}}<\mathrm{D}_{\mathrm{d} 1, \mathrm{~d} 2, \mathrm{~d} 3} \\
& \leqq \mathrm{D}_{\mathrm{b}, \mathrm{d} 1, \mathrm{~d} 2, \mathrm{~d} 3}, \\
& \text { weather category B }\end{cases} \\
& \mathrm{Y}_{\mathrm{d} 1, \mathrm{~d} 2, \mathrm{~d} 3}= \begin{cases}\mathrm{C}_{\mathrm{d} 1, \mathrm{~d} 2, \mathrm{~d} 3}, & \mathrm{D}_{b, \mathrm{~d} 1, \mathrm{~d} 2, \mathrm{~d} 3}^{\mathrm{th}}<\mathrm{D}_{\mathrm{d} 1, \mathrm{~d} 2, \mathrm{~d} 3} \\
& \leqq \mathrm{D}_{\mathrm{c}, \mathrm{d} 1, \mathrm{~d} 2, \mathrm{~d} 3},\end{cases} \\
& \text { weather category } \mathrm{C} \\
& - \\
& \mathrm{F}_{\mathrm{d} 1, \mathrm{~d} 2, \mathrm{~d} 3}, \\
& \mathrm{D}_{\mathrm{d} 1, \mathrm{~d} 2, \mathrm{~d} 3}>\mathrm{D}_{\mathrm{s}, \mathrm{d} 1, \mathrm{~d} 2, \mathrm{~d} 3}^{\mathrm{th}}, \\
& \text { weather category } \mathrm{F} \\
& \text { and above }
\end{aligned}
$$

where $Y_{d 1, d 2, d 3}$ is the weather predicted by the ana$\log$ model, $\mathrm{D}_{\mathrm{d} 1, \mathrm{~d} 2, \mathrm{~d} 3}$ is value of the decision criterion of the model for day-1, day-2 and day-3. $\mathrm{A}_{\mathrm{d} 1, \mathrm{~d} 2, \mathrm{~d} 3}, \mathrm{~B}_{\mathrm{d} 1, \mathrm{~d} 2, \mathrm{~d} 3}$, etc., are weather forecast categories and $\mathrm{D}_{\mathrm{a}, \mathrm{d} 1, \mathrm{~d} 2, \mathrm{~d} 3,}^{\mathrm{th}}, \mathrm{D}_{\mathrm{b}, \mathrm{d} 1, \mathrm{~d} 2, \mathrm{~d} 3 \text {, etc., are threshold }}^{\mathrm{th}}$ values of the decision criterion of the model for weather forecast category $A_{\mathrm{d} 1, \mathrm{~d} 2, \mathrm{~d} 3}$ and $\mathrm{B}_{\mathrm{d} 1, \mathrm{~d} 2, \mathrm{~d} 3}$, etc., respectively for day-1, day-2 and day-3. $\mathrm{F}_{\mathrm{d} 1, \mathrm{~d} 2, \mathrm{~d} 3}$ is snow day category and $\mathrm{D}_{\mathrm{s}, \mathrm{d} 1, \mathrm{~d} 2, \mathrm{~d} 3}^{\mathrm{t}}$ is threshold value of the decision criterion of the model for snow day.

Decision threshold for different weather forecast categories may be different for different mountain ranges and areas, and different for different days (day-1, day-2, day-3). The value of the decision criterion of the model lies in the range 0-100 and can never exceed 100 in any case. The high value of the decision criterion of model favours occurrence of snow day for day-1, day-2 and day-3 respectively. Therefore, threshold value of decision criteria of model for different qualitative weather forecast categories is bound by the following condition:

$$
\begin{aligned}
\mathrm{D}_{\mathrm{a}, \mathrm{d} 1, \mathrm{~d} 2, \mathrm{~d} 3}^{\mathrm{th}} & <\mathrm{D}_{\mathrm{b}, \mathrm{d} 1, \mathrm{~d} 2, \mathrm{~d} 3}^{\mathrm{th}}<\mathrm{D}_{\mathrm{c}, \mathrm{d} 1, \mathrm{~d} 2, \mathrm{~d} 3}^{\mathrm{th}} \\
& <\mathrm{D}_{\mathrm{d}, \mathrm{d} 1, \mathrm{~d} 2, \mathrm{~d} 3}^{\mathrm{th}}<\cdots<\mathrm{D}_{\mathrm{s}, \mathrm{d} 1, \mathrm{~d} 2, \mathrm{~d} 3}^{\mathrm{th}} .
\end{aligned}
$$

The decision criterion of the analog model is based on occurrence/non-occurrence of snow day in the past analog situations. Therefore, it is used for prediction of weather under different qualitative weather forecast categories. Weather forecast under operational quantitative snowfall forecast category for the day predicted as snow day by the analog model is drawn based on the mean snowfall in analog, successive situations using the following expression (Singh and Ganju 2005).

$$
X_{\mathrm{d} 1, \mathrm{~d} 2, \mathrm{~d} 3}=\frac{\sum_{r=1}^{n} X_{r}}{n},
$$

where $n=10$ (in the present case), $X_{r}$ is the snowfall observed in the $r$ th analog, successive situation.

The quantitative snowfall forecast category (table 1) is assigned to any snow day to which the predicted snowfall amount belongs for day-1, day-2 and day-3 and the analog model predicts snow day with quantitative snowfall forecast category. The developed analog model produces weather forecast in operational weather forecasting mode three days in advance.

The analog model predictions are compared with the two standards of reference namely: a climatological forecast and persistence forecast. The climatological forecast is mean snowfall recorded in the past on the same day (Julian). As evident, it is a constant forecast for all three days. A persistence forecast for day-1 consists of the recorded snowfall one day before the day in question (forecast day). The persistence forecasts produced on the basis of recorded snowfall one day before the day in question (initial day) for day-2 and day-3 may lead to very inaccurate predictions. Therefore, we have considered persistence forecast for day-1 only.

For this particular purpose, any day predicted with snowfall amount $\geqq 1.0 \mathrm{~cm}$ (best accuracy of snowfall measurements in the past) by persistence and climatological forecast is taken as snow day otherwise no-snow day. The quantitative snowfall category (table 1) is assigned to any snow day to which the predicted snowfall amount belongs. 
Table 3. $2 \times 2$ contingency table for evaluation of performance of persistence, climatological forecast and the analog model forecast for prediction of snow day and no-snow day (winter 2003-2004 to winter 2006-2007, S = snow day, NS = no-snow day).

\begin{tabular}{|c|c|c|c|c|c|c|c|c|c|c|c|}
\hline \multirow[b]{4}{*}{ Mountain range/area } & \multirow[b]{4}{*}{ Observed } & \multicolumn{10}{|c|}{ Forecast } \\
\hline & & \multirow{2}{*}{\multicolumn{2}{|c|}{$\begin{array}{c}\begin{array}{c}\text { Climatological } \\
\text { forecast }\end{array} \\
\text { Day-1 }\end{array}$}} & \multirow{2}{*}{\multicolumn{2}{|c|}{$\begin{array}{c}\begin{array}{c}\text { Persistence } \\
\text { forecast }\end{array} \\
\text { Day-1 }\end{array}$}} & \multicolumn{6}{|c|}{ Analog forecast } \\
\hline & & & & & & \multicolumn{2}{|c|}{ Day-1 } & \multicolumn{2}{|c|}{ Day-2 } & \multicolumn{2}{|c|}{ Day-3 } \\
\hline & & $\mathrm{S}$ & NS & $\mathrm{S}$ & NS & $\mathrm{S}$ & NS & $\mathrm{S}$ & NS & $\mathrm{S}$ & NS \\
\hline \multirow[t]{2}{*}{ Samsabari range } & $\mathrm{S}$ & 186 & 30 & 127 & 89 & 156 & 60 & 115 & 101 & 113 & 103 \\
\hline & NS & 370 & 138 & 50 & 458 & 73 & 435 & 109 & 399 & 151 & 357 \\
\hline \multirow{2}{*}{$\begin{array}{l}\text { Pir Panjal } \\
\text { range }(\mathrm{HP})\end{array}$} & $\mathrm{S}$ & 95 & 10 & 56 & 49 & 68 & 37 & 46 & 58 & 39 & 64 \\
\hline & NS & 335 & 102 & 34 & 403 & 44 & 393 & 78 & 360 & 76 & 363 \\
\hline \multirow{2}{*}{$\begin{array}{l}\text { Pir Panjal } \\
\quad \text { range }(J \& K)\end{array}$} & $\mathrm{S}$ & 135 & 53 & 104 & 84 & 119 & 69 & 85 & 103 & 66 & 122 \\
\hline & NS & 322 & 212 & 45 & 489 & 72 & 462 & 105 & 429 & 126 & 408 \\
\hline \multirow{2}{*}{$\begin{array}{l}\text { Great Himalayan } \\
\text { range }(\mathrm{HP})\end{array}$} & $\mathrm{S}$ & 142 & 27 & 77 & 92 & 88 & 81 & 62 & 108 & 42 & 128 \\
\hline & NS & 425 & 128 & 66 & 487 & 48 & 505 & 90 & 462 & 79 & 473 \\
\hline \multirow{2}{*}{$\begin{array}{l}\text { Great Himalayan } \\
\text { range }(J \& K)\end{array}$} & $\mathrm{S}$ & 139 & 50 & 95 & 94 & 115 & 74 & 76 & 112 & 45 & 143 \\
\hline & NS & 357 & 177 & 73 & 461 & 87 & 447 & 131 & 404 & 101 & 434 \\
\hline \multirow[t]{2}{*}{ Karakoram range } & $\mathrm{S}$ & 254 & 21 & 150 & 125 & 199 & 76 & 158 & 117 & 159 & 116 \\
\hline & NS & 415 & 28 & 72 & 371 & 144 & 299 & 211 & 232 & 243 & 200 \\
\hline
\end{tabular}

\section{Results and discussion}

The analog weather forecast model is tested with independent dataset of more than 717 days (542 days of Pir Panjal range in HP) of the past four winters (winter 2003-04 to winter 2006-07). Weather forecasts are verified at the reference station in each mountain range and area, and various statistical accuracy measures considered for evaluation of qualitative weather forecast (snow day/nosnow day) are given in appendix B (Mohanty and Dimri 2004; Wilks 1995). The $2 \times 2$ contingency table for evaluation of performance of persistence, climatological and analog model for qualitative weather prediction is given in table 3 and various statistical accuracy measures are given in table 4. The overall accuracy (PC) of climatological and persistence forecast for qualitative weather prediction is in the range $36.3-48.1 \%$ and $72.6-84.7 \%$ respectively for day- 1 predictions over different mountain ranges and areas. It is in the range $69.4-85.1 \%, 54.3-74.9 \%$ and $50.0-74.2 \%$ for the analog model for day-1, day-2 and day-3 predictions respectively (table 4 ). The POD of climatological forecast is better than persistence and analog forecast for all the mountain ranges and areas in NW-Himalaya (table 4). The overall performance of climatological forecast is poor compared to persistence and analog forecast due to its high FAR. The overall accuracy of the analog model is better than persistence forecast (table 4) for day-1 predictions. The POD of analog model is significantly better than POD of persistence forecast for all the mountain ranges and areas for qualitative weather prediction. However, the FAR of analog model is marginally more than persistence forecast. The performance of the analog model decreases for qualitative weather prediction for day-2 and day-3 predictions compared to day- 1 predictions. Decrease in performance of the analog model is more for prediction of snow day compared to prediction of no snow day (tables 3 and 4) for all the mountain ranges and areas in NW-Himalaya for qualitative weather prediction.

The overall accuracy, percentage of snowfall categories observed in the predicted snowfall categories, for quantitative categorical snowfall prediction by climatological and persistence forecast for day-1 predictions and analog model for three days predictions is shown in figure 2. The overall accuracy of the analog model is better than persistence and climatological forecast for day-1 predictions at most of the mountain ranges and areas (figure 2). The mean accuracy of the analog model is marginally better than persistence and climatological forecast for day- 1 predictions. This is due to poor performance of the analog model for Pir Panjal range in $J \& K$ and Karakoram range. The quantitative categorical snowfall forecast error, percentage of snowfall categories recorded outside \pm 1 category of predicted snowfall category, of the analog model is less than persistence and climatological forecast for all mountain ranges and areas (figure 2). The mean error in quantitative categorical snowfall prediction of the analog model is less than persistence and climatological forecast 


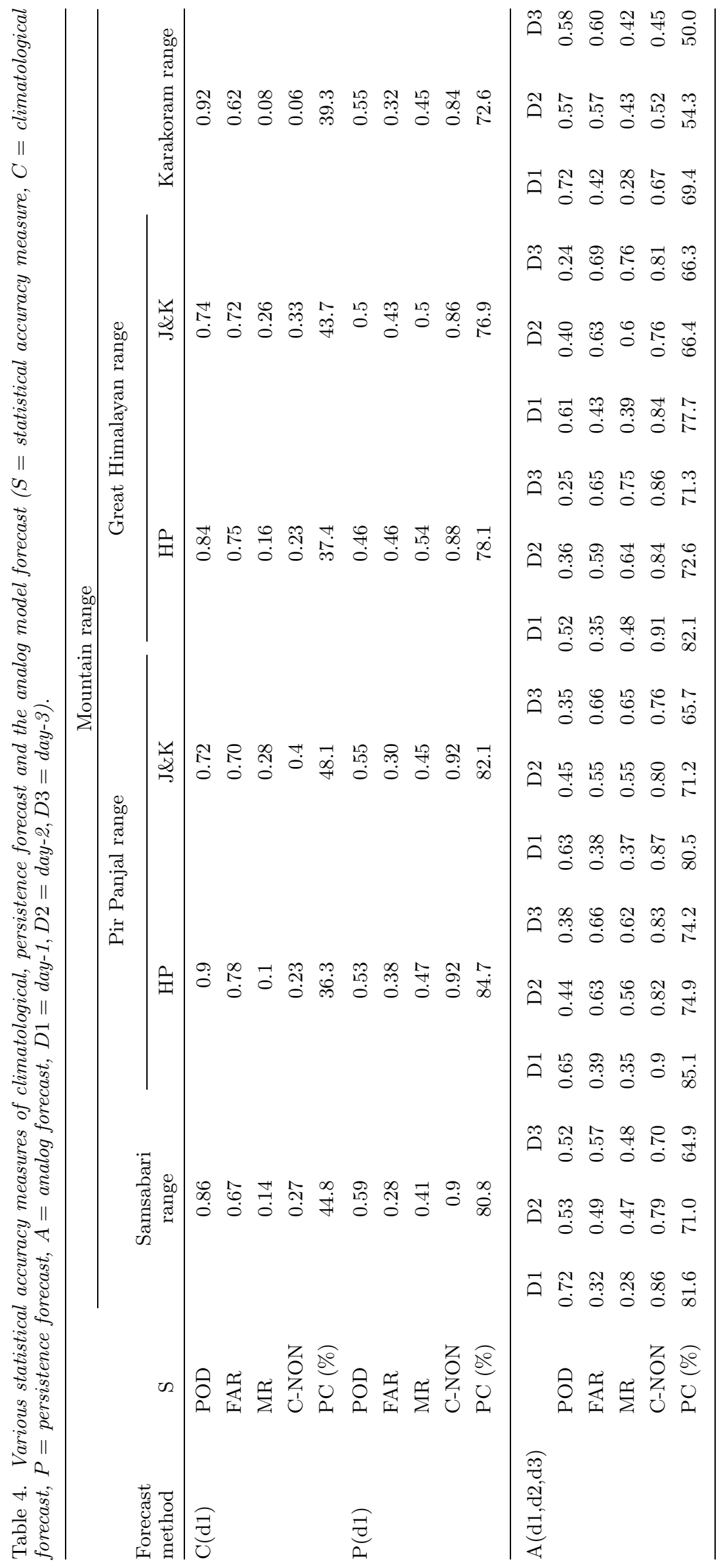




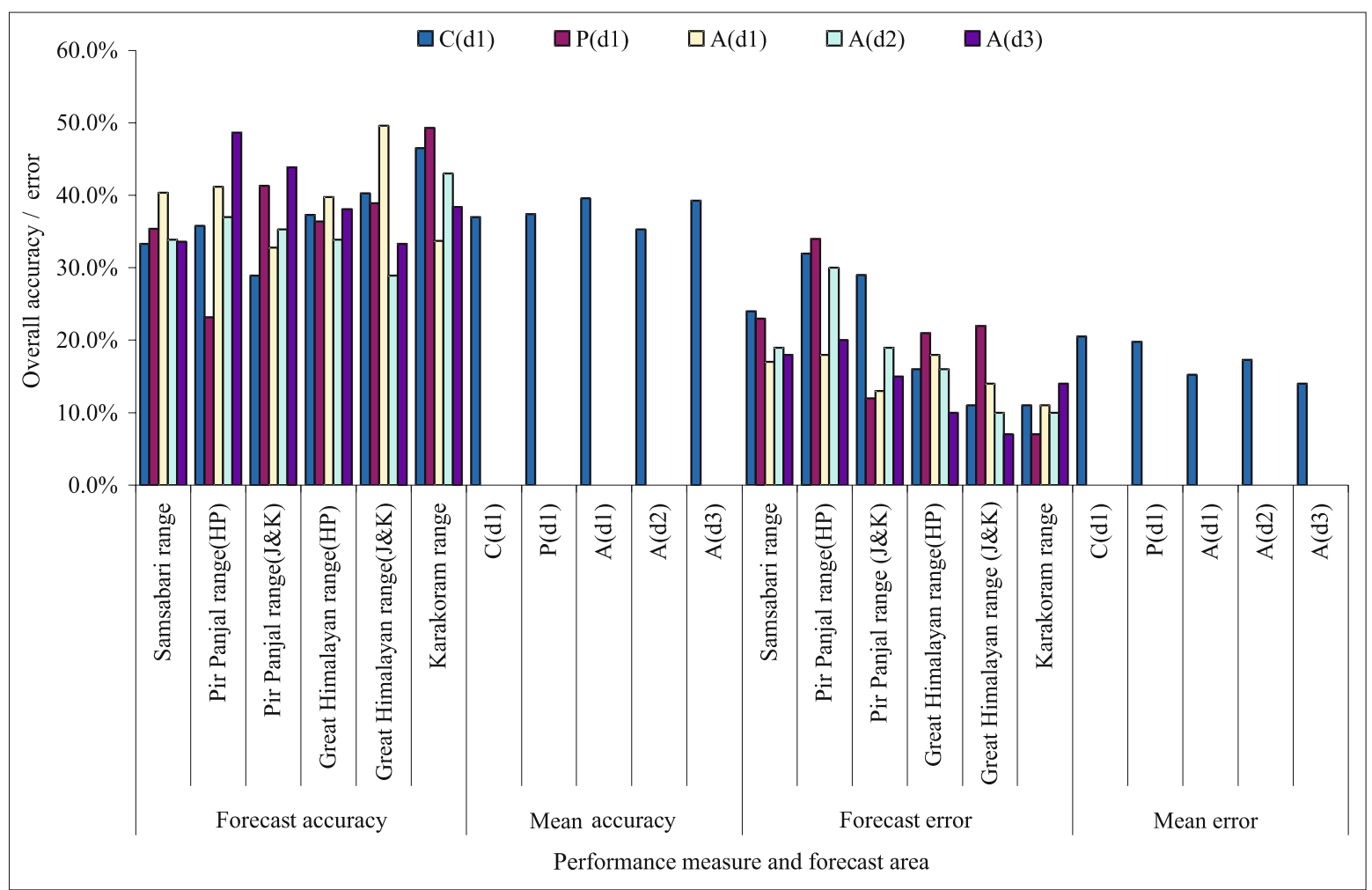

Figure 2. Performance of persistence, climatological and analog model for quantitative categorical snowfall prediction over different mountain ranges and areas in NW-Himalaya $(\mathrm{C}(\mathrm{d} 1)=$ climatological forecast $($ day -1$), \mathrm{P}(\mathrm{d} 1)=$ persistence forecast $($ day-1), $\mathrm{A}(\mathrm{d} 1)=$ analog forecast $($ day- 1$), \mathrm{A}(\mathrm{d} 2)=$ analog forecast (day-2), $\mathrm{A}(\mathrm{d} 3)=$ analog forecast $($ day-3)).

for day-1 predictions. The overall accuracy of the analog model for quantitative categorical snowfall prediction does not decrease and quantitative categorical snowfall forecast error does not increase significantly for day-2 and day-3 predictions compared to day-1 predictions (figure 2). Prediction of more number of snow days with better quantitative categorical snowfall accuracy with least quantitative categorical snowfall forecast error compared to persistence and climatological forecast suggest that the analog model performs best among the three for day-1 predictions.

The analog model has been developed for forecasting weather in operational weather forecasting mode (table 1). Therefore, model performance under each operational weather forecast category is presented as the number of snow days and number of no-snow days observed under that category for each mountain range and area for all three days. The overall accuracy of model for each mountain range and area is presented as per cent correct prediction of snow day and no-snow day, when weather is predicted under snow day and no-snow day weather forecast categories.

Weather forecast categories A, B, C and D represent no-snow day and weather forecast categories F, G, H, I, J and $\mathrm{K}$ represent snow day (table 1). Weather forecast category $\mathrm{E}$ represents snowfall at isolated places $(<25 \%$ area). Exact verification of weather forecast under weather forecast category $\mathrm{E}$ is difficult due to lack of dense observatory network over the NW-Himalaya. Further, model is verified according to weather reported at the reference observatory in each mountain range and area. Therefore, the overall performance of the analog weather forecast model for prediction of snow day and no-snow day in each mountain range and area is presented keeping weather forecast category E under no-snow day category (table 1) for simplicity.

The performance of the analog weather forecast model for predicting weather under operational weather forecast categories for Samsabari range and Pir Panjal range is given in table 5 and it is given in table 6 for great Himalayan range and Karakoram range. The analog model predicts fair weather (weather forecast category A) 269 days for day-1, 243 days for day-2 and 180 days for day-3 forecast for Samsabari range (table 5). Among the predicted days, 260 days for day-1, 214 days for day- 2 and 160 days for day-3 are observed as no-snow day for Samsabari range (table 5). Similar distribution of observed snow days and no-snow days for each weather forecast category and each mountain range for day-1, day- 2 and day- 3 predictions is given in tables 5 and 6 . 


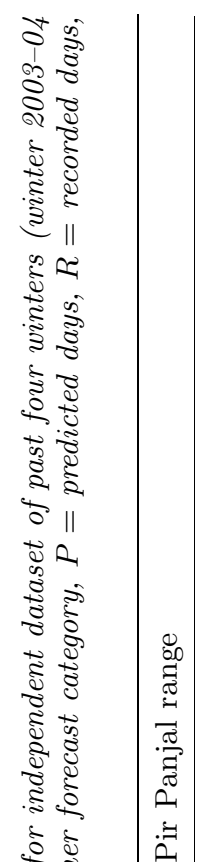

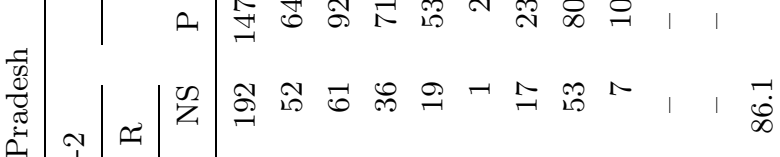

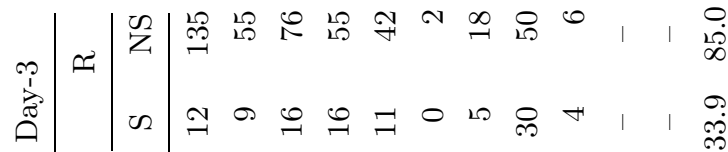
预 苛

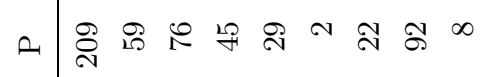

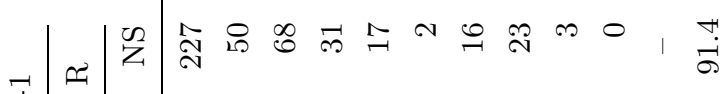
ค

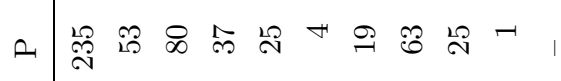

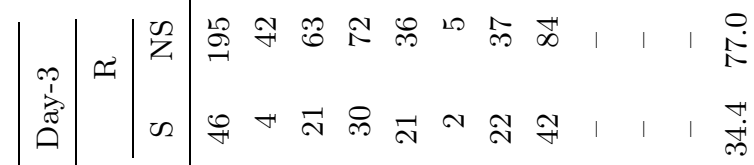

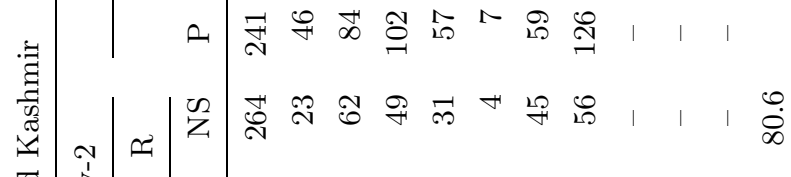

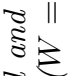
๑ั

要

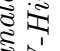

$\stackrel{2}{2}$

马า

ช.

है छे

तु है है

这. हुँ

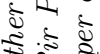
8

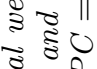
โิ้ ठ․ 용 ㄷㅀㅇำ कू हो हो ธิँ ปे 종 औ น

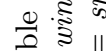

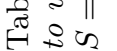

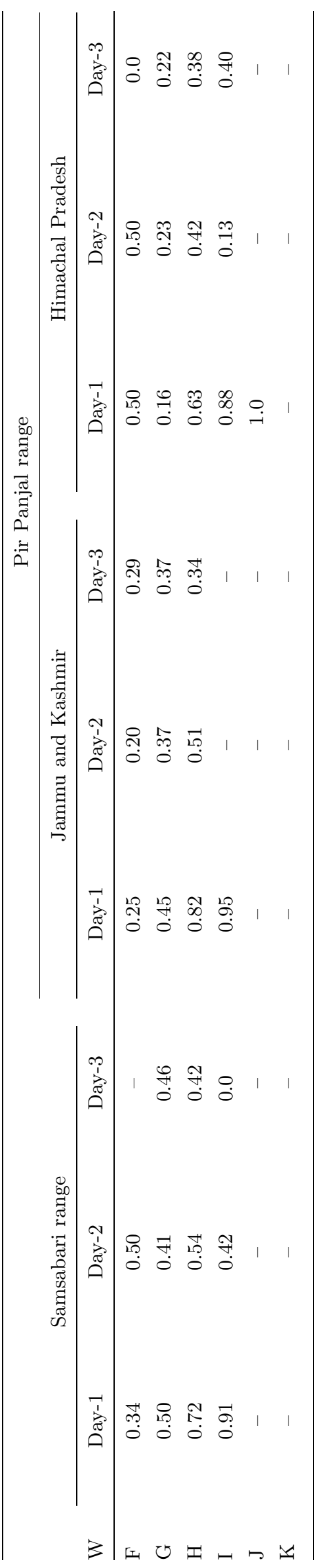




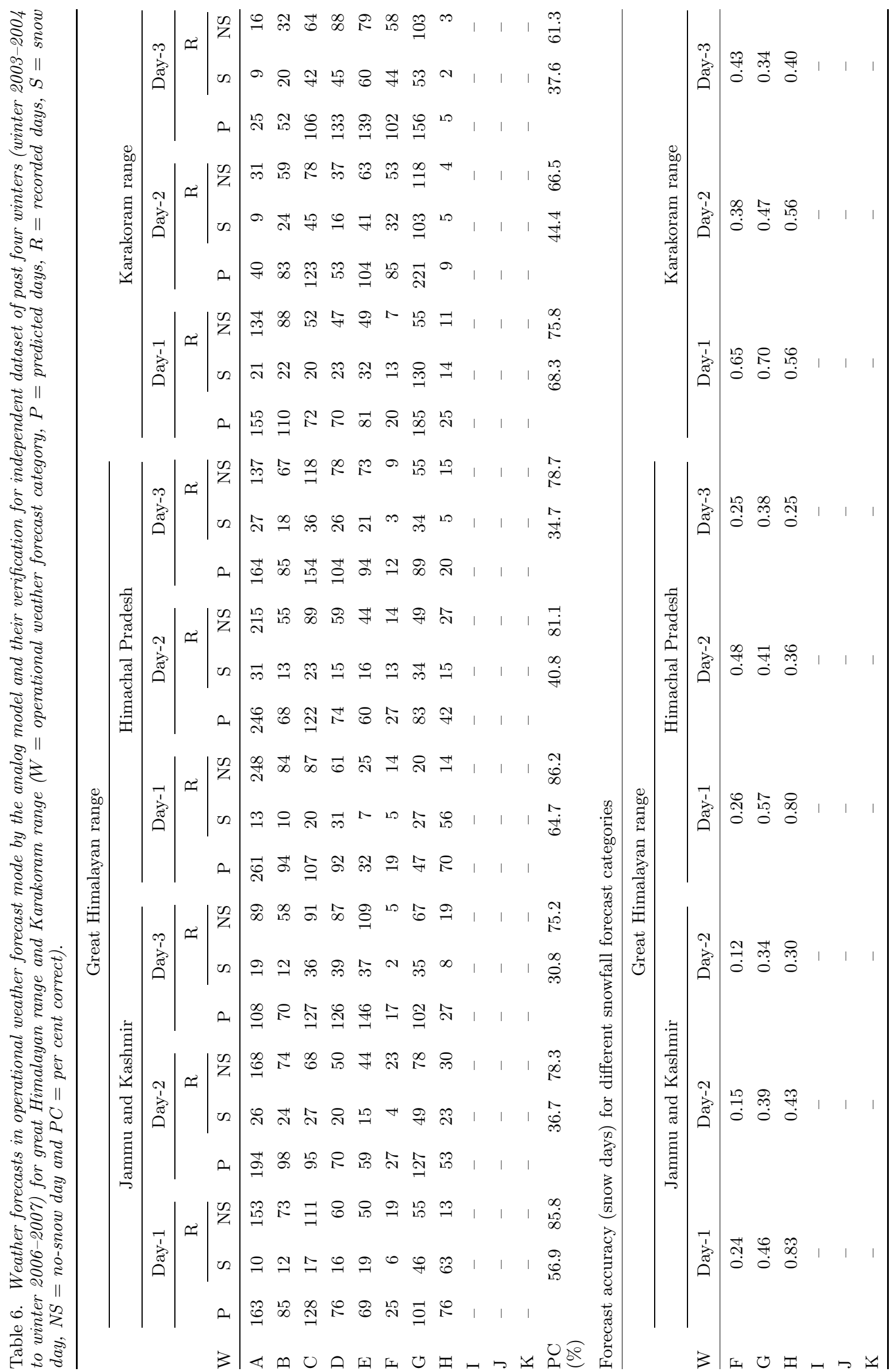




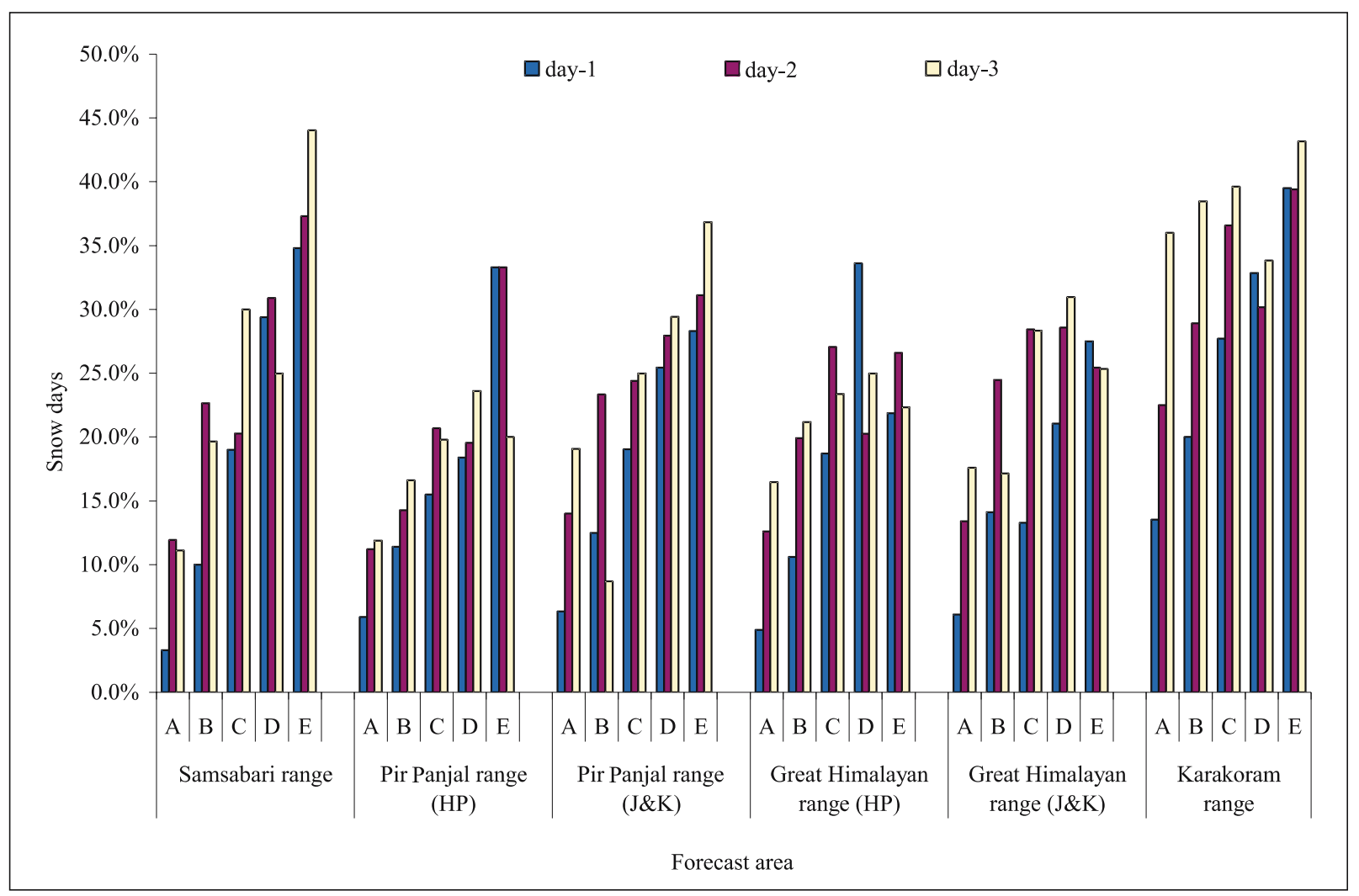

Figure 3. Prediction errors of the analog weather forecast model for snow day weather forecast categories for day-1, day-2 and day-3 forecast over different mountain ranges and areas in NW-Himalaya.

Considering all three days forecast together, the overall accuracy of the analog forecast model is $68.1-42.8 \%, 62.3-33.9 \%, 64.7-30.8 \%, 68.3-37.6 \%$ for prediction of snow day and it is $87.9-77.6 \%$, $91.4-77.0 \%, 86.2-75.2 \%, 75.8-61.3 \%$ for no-snow day for Samsabari range, Pir Panjal range, great Himalayan range and Karakoram range respectively. The overall accuracy of the analog weather forecast model decreases as the lead time of the forecast increases for each mountain range and area. However, a significant difference exists in the overall accuracy of the model for prediction of snow and no-snow day for different mountain ranges (Samsabari range and Pir Panjal range) and different areas in the same mountain range (Pir Panjal range in $\mathrm{HP}$ and $\mathrm{J} \& \mathrm{~K})$. Considering all three days forecasts, $7-8 \%$ difference in the forecast accuracy of snow and no-snow days is found for Pir Panjal range in HP and Pir Panjal range in J\&K (table 5). Similar difference in the prediction of snow and nosnow day is found for great Himalayan range in HP and great Himalayan range in J\&K (table 6). The overall accuracy of the analog weather forecast model for prediction of snow and no-snow day for great Himalayan range in HP is found better compared to great Himalayan range in $J \& K$ for all three days (table 6). The overall accuracy of the analog weather forecast model is found better when weather is predicted under no-snow day weather forecast categories compared to snow day weather forecast categories for all three days. This may be due to dominance of no-snow days over snow days. Therefore, forecast accuracy of snow day, proportion of snow days under each operational snowfall forecast category, is also considered and are given in tables 5 and 6 for each mountain range and area. The forecast accuracy of the analog model is more for heavy snowfall categories compared to low snowfall categories (tables 5 and 6 ). The forecast accuracy of snow day decreases under each weather forecast category as the lead time of forecast increases (day-2 and day-3).

The analog weather forecast model is developed for forecasting weather in operational weather forecasting mode for different mountain ranges in NWHimalaya. Therefore, it is necessary to consider prediction error and its trend for day-1, day-2 and day-3 forecast for each weather forecast category and for each mountain range. Prediction error and its trend for day-1, day-2 and day-3 forecast for each weather forecast category belonging to no-snow day category is presented as the percentage of snow days (figure 3 ) and it is presented as percentage of no-snow days belonging to 


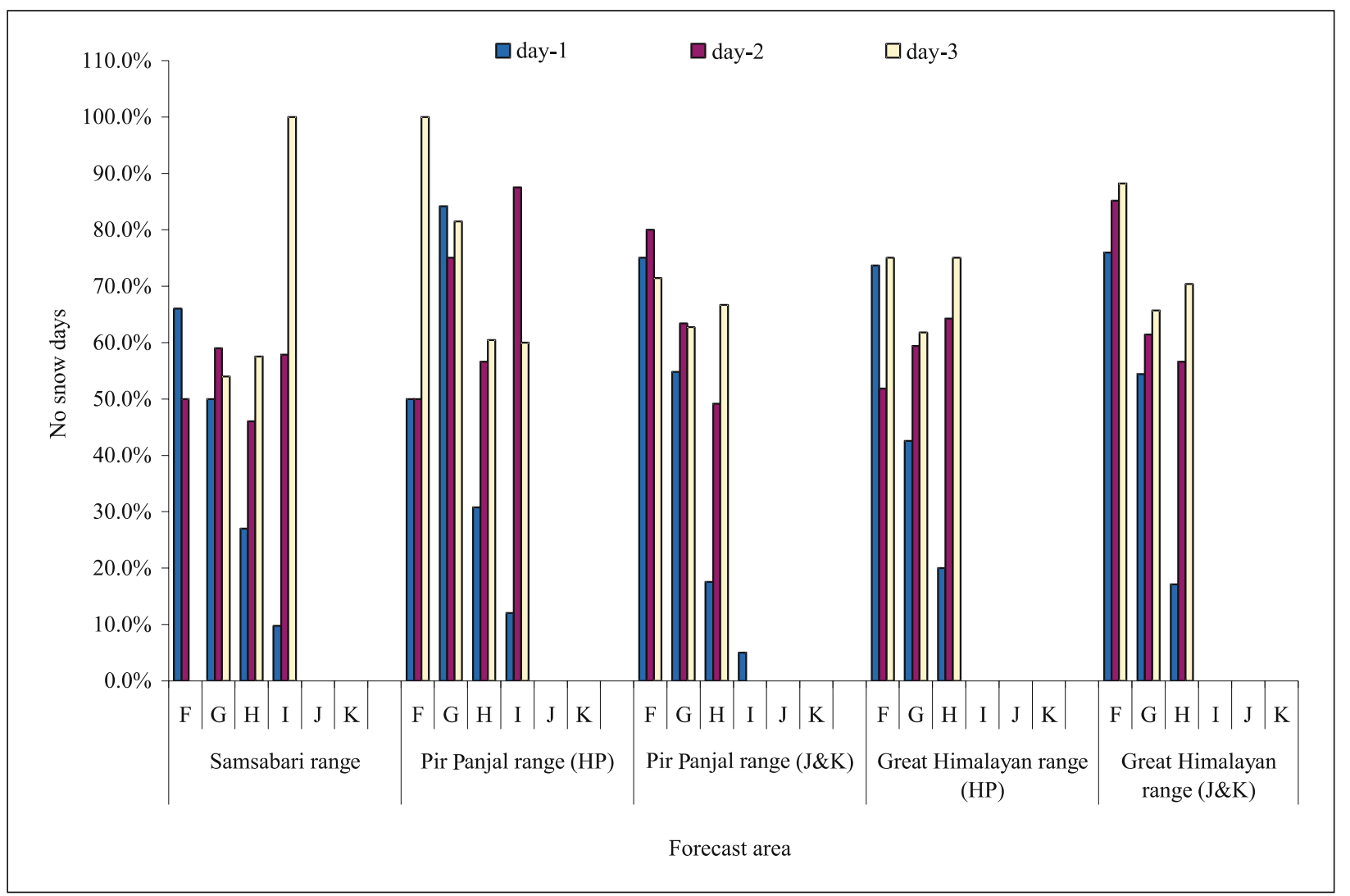

Figure 4. Prediction errors of the analog weather forecast model for no-snow day weather forecast categories for day-1, day- 2 and day-3 forecast over different mountain ranges and areas in NW-Himalaya.

snow day categories (figure 4). Percentage of snow days increases for weather predicted under categories $\mathrm{A}$ to $\mathrm{E}$ for all three days and accuracy of prediction under each forecast category decreases day-1 through day-3 (figure 3). Percentage of nosnow days decrease for weather predicted under forecast categories $\mathrm{F}$ to I for day-1 predictions (figure 4). However, percentage of no-snow days, generally, increases for categories $\mathrm{H}$ and above for day-2 and day-3 predictions. This is due to very less number of days being predicted under these categories (tables 5 and 6 ) for day-2, day-3 forecast and model failed to predict them accurately (model predicts 2 days under weather category I for day-3 forecast in Samsabari range and both the days are reported as no-snow days). Increasing trend of snow days for weather forecast categories A to E and decreasing trend of no-snow days for weather forecast categories $\mathrm{F}$ to I indicates that the analog model is capable of capturing deteriorating state of weather for both the cases. However, high forecast error under weather forecast categories C, D, E for no-snow day and F, G for snow day is due to very less number of days predicted under these forecast categories and model could not capture actual snow day and no-snow day event.

\section{Summary and conclusion}

Mountain range specific analog weather forecast model is tested with the independent dataset of the past 4 winters (winter 2003-2004 to winter 2006-2007). The results are reasonably good for prediction of weather in operational weather forecasting mode over different mountain ranges and areas in NW-Himalaya. Results suggest that there is some possibility of prediction of weather in operational weather forecasting mode over different mountain ranges in NW-Himalaya employing the analog method. Significant difference in overall accuracy for prediction of snow day and nosnow day is found for different mountain ranges as well as different areas in same mountain range in NW-Himalaya. These are some interesting facts that highlight the need of mountain range specific weather forecast model for the NWHimalaya. Comparative study of persistence, climatological and analog forecast for qualitative weather and quantitative categorical snowfall prediction shows that analog model performs better than climatological and persistence forecast for qualitative weather and quantitative categorical snowfall forecast for day-1 predictions for all 
mountain ranges except for Karakoram range in NW-Himalaya.

The analog weather forecast model is developed with the data of few winters (maximum 17 winters) only. The model accuracy is supposed to improve once the size of dataset increases over time with the hope that better analogs may be found in a large dataset. At present, model is tested only for prediction of snow day and no-snow day under different operational weather forecasting categories and more rigorous testing of model for prediction of weather under each operational weather forecasting category is needed. Inclusion of more data like upper air observations, satellite data and optimal combination of numerical prediction model (NWP models) with the analog weather forecast model may lead to better results for prediction of weather in operational weather forecasting mode over different mountain ranges in NW-Himalaya.

\section{Acknowledgements}

The authors are very thankful to Dr. R N Sarwade, Director, SASE for his constant encouragement during this study. The study would not have been possible without efforts of the scientists and technical assistants of Avalanche Forecasting Group, who collected the data under harsh climatic conditions in a remote snow bound areas.

\section{Appendix A}

Surface weather parameters used for development of analog weather forecast model

1. Maximum temperature $\left({ }^{\circ} \mathrm{C}\right)$

2. Minimum temperature $\left({ }^{\circ} \mathrm{C}\right)$

3. Ambient temperature $\left({ }^{\circ} \mathrm{C}\right)$

4. Relative humidity (\%)

5. Cloudiness (Octa)

6. Cloud type (Coded number)

7. Spot wind speed $(\mathrm{km} / \mathrm{h})$

8. Average wind speed $(\mathrm{km} / \mathrm{h})$

9. Weather code (Coded number)

10. Atmospheric pressure (mb)

11. Sunshine duration $(\mathrm{h})$

\section{Appendix B}

(Verification measures used for forecast evaluation)

\begin{tabular}{llcc}
\hline & & \multicolumn{2}{c}{ Forecast } \\
\cline { 3 - 4 } & & Yes & No \\
\hline \multirow{2}{*}{ Observed } & Yes & A & B \\
& No & C & D \\
\hline
\end{tabular}

Probability of detection $(\mathrm{POD})=A /(A+B)$

False alarm rate $(\mathrm{FAR})=C /(A+C)$

Miss rate $(\mathrm{MR})=B /(A+B)$

Correct non-occurrence $(\mathrm{C}-\mathrm{NON})=D /(C+D)$

Per cent correct $(\mathrm{PC})$

$=100 \times(A+D) /(A+B+C+D)$.

\section{References}

McClung D and Schaerer P 1993 The avalanche handbook; The mountaineers, Seattle, Washington.

Mohanty U C and Dimri P 2004 Location specific prediction of the probability of occurrence and quantity of precipitation over the Western Himalayas; Wea. Forecasting 19 420-429.

Perla R I 1970 On the contributory factors in the avalanche hazard evaluation; Canadian Geotechnical Journal $\mathbf{7}$ 414-419.

Sharma S S and Ganju A 2000 Complexities of avalanche forecasting in Western Himalaya: An overview; Cold Regions Science and Technology 31 95-102.

Singh A and Ganju A 2004 A supplement to nearest neighbour method for avalanche forecasting; Cold Regions Science and Technology 39 105-113.

Singh D, Singh A and Ganju A 2005 Weather forecasting using nearest neighbour model; Curr. Sci. 88 1283-1289.

Singh D and Ganju A 2006 Improvement in nearest neighbour weather forecast model performance while considering previous day's forecast for drawing forecast for the following day; Curr. Sci. 91 1686-1691.

Van den Dool H M 1989 A new look at weather forecasting through analogues; Mon. Wea. Rev. 117 2230-2247.

Zorita E and Von Storch H 1999 The analog method as a simple statistical downscaling technique: Comparison with more complicated methods; J. Climate 12 $2474-2489$

Wilby R L and Wigley T M L 1997 Downscaling general circulation model output: A review of methods and limitations; Prog. Phys. Geogr. 21 530-548.

Wilks D S 1995 Statistical methods in atmospheric sciences; Academic Press, United Kingdom. 